\title{
A Research Brief: The Current State of Quality Clinical Placement in Nursing Practicums
}

\author{
Esther O. Park ${ }^{1} \&$ Gloria Y. Nam ${ }^{2}$ \\ ${ }^{1}$ Assistant Professor, RN, PhD., Daegu University, Daegu 42400, South Korea \\ ${ }^{2}$ Clinical Adjunct Faculty, University of Washington, Seattle, USA. \\ Correspondence: Gloria Y. Nam, RN, FNP-BC, PhD., Clinical Adjunct Faculty, University of Washington, 1959 \\ NE Pacific St, Seattle, WA 98195 USA. E-mail: gloriayjn@gmail.com
}

Received: December 5, 2016

Accepted: December 13, 2016

Online Published: December 19, 2016

doi:10.20849/ijsn.v1i1.100

URL: http://dx.doi.org/10.20849/ijsn.v1i1.100

\begin{abstract}
Purpose: The study was conducted to investigate students' perceptions on their clinical experience and the quality clinical placement.

Methods: This was a cross-sectional descriptive study. One hundred and thirteen junior or senior nursing students participated in this study. Descriptive statistics were used to analyze the data.

Results: Majority nursing students expressed un-satisfaction (57.52\%) with the required hours of practicums. They experienced different quality of clinical placement between the cities. Direct nursing skills they practice were limited to doing chores $(67.1 \%)$, charting $(14.47 \%)$, providing education to patients and families $(10.53 \%)$, giving medication (7.89\%). $49.56 \%$ of the students did not satisfy with what they have received shift schedule which was given from hospitals.
\end{abstract}

Conclusion: Simulation and scenario-centered education should be considered in Asian countries as one of replacement of clinical hours on-site. Future research warrants testing and clarifying the most appropriate clinical hours to the nursing undergraduates for their quality clinical placement.

Keywords: quality clinical placement, simulation/scenario-centered education, clinical practicum

\section{Introduction}

High quality of clinical placement functions a pivotal part of nursing students' progress to being well-prepared nursing professionals (Ford et al., 2016) and these placements also act as an important bridge from theoretical knowledge to practical application (Arieli, 2013). While much attention has been paid to the importance of quality clinical placement, reality shows the process of finding these to be difficult. Over the past few decades, nursing staff shortage has been a global issue among health care systems leading to an increase in nursing school enrollment around the globe (Betony, 2012; Song \& Kim, 2013). This has resulted in an increased demand everywhere for clinical placements and has led to issues in maintaining a level of quality within clinical placements (Ford et al., 2016). A few studies have focused on this issue (Cheng \& Liou, 2013; Courtney-Pratt et al., 2013; Forber et al., 2015; Ford et al., 2016; Song \& Kim, 2013), but these investigated the topic from an angle of stakeholders, nursing supervisors, preceptors and/or medical systems. No study focusing on students' perception on the quality of clinical placement has been found.

An increase in number of nursing students affects demand for clinical placement at qualified health care systems. Further, the number of health organizations and clinical placement sites has not grown at the same speed as the growth in number of nursing students (Song \& Kim, 2013). Thus, the needs of clinical placement for the increase in students has become a burden not only to nursing school to find qualified sites but also to health organizations that accept nursing students (Ford et al., 2016). This often results in clinical hours being less about applying knowledge and more about just passing time on the clinical sites for students. If nursing licensure continues to require a specific number of clinical onsite practicum hours, the quality of clinical placement would be then dropped since the number of nursing schools, which are mostly depending on clinical sites for their practicum, has at least doubled for a past decade. Faced with these statistics, it is imperative that nursing education professionals work together to reconsider the amount of clinical practicum hours required for students. As a 
preliminary stage, this study was designed to investigate students' perception of the quality and appropriateness of the required hours of their clinical practicums.

Recently, patient acuity has increased (Ahn, Ahn, \& Park, 2009) and more sophisticated nursing skills to handle medical instruments (i.e., Extra-Corporal Membrane Oxygenation (ECMO), Intra-Aortic Balloon Pump (IABP), Continuous Veno-Venous Hemofiltration $(\mathrm{CVVH})$ ) and dealing with complicated cases are required. Although the recent complexity of clinical situations, the model of students' supervision has not kept up with the changes (Courtney-Pratt et al., 2013). Some have insisted that encouraging a one-to-one relationship between students and onsite clinical placement supervisor would be more effective for nursing students to develop principal nursing skills prior to their graduation (Courtney-Pratt et al., 2013; Forber et al., 2015). However, this seems not applicable since experiencing quality clinical placement having a one-to-one relationship is getting more difficult. Therefore, this study will discuss the current imbalance between demand for clinical placement and lack of availability of clinical sites for nursing practicum.

\section{Methods}

This was a cross-sectional descriptive study. The study sample was collected using a snowballing of convenience sampling. The study participants were selected if they were either male or female nursing students who were at the junior or senior level of their education. Originally, 10 students from the university where the first author taught agreed to participate in this study. Those 10 students then spoke with their nursing student-colleagues to spread the word about the study, which was the snowballing method in practice. The purpose of this study, the voluntary nature of participation, and participants' right to refuse to participate were explained to those who expressed an interest. The study participants were explained that their refusal would not have any unfavorable consequence.

The self-reported questionnaire was designed as an electronic survey and distributed electronically from August to September, 2016. Nursing students who initially received an email explaining they could decline to proceed or could agree to the study by clicking on a hyperlink embedded in the email. If they did not want to participate, they ignored the email. Once they clicked the hyperlink, the page was then proceeded to the questionnaire. There was no way to identify the participants so that the confidentiality was assured.

This study was approved by an institutional review board at the first author's institution in September, 2016. This was exempted and expedited to review with the existing de-identified data. Descriptive statistics were used to analyze the data. In addition, G-power analysis was employed to justify the sample size. Using the G-power analysis, the justified sample size was 92 with effect size .2, study power .9 , and alpha level of .01 . To take attrition rate into account, 200 emails were distributed and the online survey reported 113 responses.

\section{Results}

\subsection{Demographic Characteristics}

The majority of the participants were female $(\mathrm{N}=105)$; only 8 male students participated. The average age of the study sample was 22.3 years old (Standard Deviation $(\mathrm{SD})=1.04)$. Of the entire sample, most $(88.5 \%)$ were in their junior year of nursing school, while $11.5 \%$ were in their senior year. Students from 11 different universities participated (See Table 1). The majority $(51.33 \%)$ had completed the first semester of practicum. Then, some completed 4 semesters (11.5\%), 3 semesters $(25.66 \%)$, and 2 semesters $(12.39 \%)$. 
Table 1. Descriptive results $(\mathrm{N}=113)$

\begin{tabular}{|c|c|c|c|c|c|}
\hline Gender & $\begin{array}{c}\text { Age } \\
\text { Mean }(* \mathrm{SD})\end{array}$ & $\begin{array}{l}\text { Level of } \\
\text { education }\end{array}$ & $\begin{array}{c}\text { Number of } \\
\text { universities } \\
\text { where the } \\
\text { samples in } \\
(\mathrm{N}=11)\end{array}$ & $\begin{array}{l}\text { Practicum } \\
\text { semesters }\end{array}$ & $\begin{array}{c}\text { Amount of } \\
\text { total } \\
\text { practicum } * \text { hrs }\end{array}$ \\
\hline $\begin{array}{l}\text { Female } 105 \\
\text { Male } 8(7.08 \%)\end{array}$ & \multirow[t]{2}{*}{$22.3(1.04)$} & $\begin{array}{l}\text { Junior } 100 \\
(88.5 \%)\end{array}$ & $\begin{array}{l}A=10 \\
B=10\end{array}$ & $\begin{array}{l}1=58 \\
(51.33 \%)\end{array}$ & $\begin{array}{l}\text { Satisfied }=48 \\
(42.48 \%)\end{array}$ \\
\hline No answer 1 & & $\begin{array}{l}\text { Senior } 13 \\
(11.5 \%)\end{array}$ & $\begin{array}{l}\mathrm{C}=14 \\
\mathrm{D}=11 \\
\mathrm{E}=1 \\
\mathrm{~F}=12 \\
\mathrm{G}=30 \\
\mathrm{H}=1 \\
\mathrm{I}=8 \\
\mathrm{~J}=15 \\
\mathrm{~K}=1\end{array}$ & $\begin{array}{l}2=14 \\
(12.39 \%) \\
3=29 \\
(25.66 \%) \\
4=11 \\
(9.73)\end{array}$ & $\begin{array}{l}\text { Unsatisfied } \\
=65(57.52 \%)\end{array}$ \\
\hline $\begin{array}{l}\text { Ideal length of } \\
\text { practicum } \\
(* \text { hr/week })\end{array}$ & $\begin{array}{l}\text { Reason of } \\
\text { un-satisfaction with } \\
\text { the length }\end{array}$ & $\begin{array}{l}\text { Difference } \\
* \mathrm{~b} / \mathrm{w} \text { cities }\end{array}$ & $\begin{array}{l}\text { Include } \\
\text { sim/scenario } \\
\text { class to } \\
\text { practicum } \\
\text { by1:1ratio }\end{array}$ & $\begin{array}{l}\text { Direct } \\
\text { nursing } \\
\text { skills } \\
\text { practiced }\end{array}$ & $\begin{array}{l}\text { Satisfaction } \\
\text { with shift } \\
\text { schedule (Day, } \\
* \text { Split, } \\
\text { Evening) }\end{array}$ \\
\hline \multirow{6}{*}{$\begin{array}{l}10 \mathrm{hr}=7.08 \% \\
20 \mathrm{hr}=20.35 \% \\
30 \mathrm{hr}=35.19 \% \\
\text { No answer }= \\
37.17 \%\end{array}$} & \multirow[t]{2}{*}{ Too long $=22.12 \%$} & Yes $=$ & Yes $=$ & Chores $=$ & \multirow{6}{*}{$\begin{array}{l}\text { Yes }=50.44 \% \\
\text { No }= \\
49.56 \% \\
\text { Reason: given } \\
\text { by demand } \\
\text { and supply } \\
\text { situation of the } \\
\text { unit }\end{array}$} \\
\hline & & $78.79 \%$ & $70.79 \%$ & $45.13 \%$ & \\
\hline & Too short $=.88 \%$ & No $=21.21 \%$ & $\mathrm{No}=$ & Charting $=$ & \\
\hline & \multirow{3}{*}{$\begin{array}{l}\text { Non-nursing job } \\
\text { (transferring *pt., } \\
\text { chores, etc.) }=76.99 \%\end{array}$} & & $29.2 \%$ & $9.73 \%$ & \\
\hline & & & & $\begin{array}{l}\text { Education }= \\
7.08 \% \\
\text { Medication= } \\
5.31 \%\end{array}$ & \\
\hline & & & & $\begin{array}{l}\text { No answer }= \\
32.74 \%\end{array}$ & \\
\hline
\end{tabular}

$* \mathrm{SD}=$ Standard Deviation, $* \mathrm{~b} / \mathrm{w}=$ between, $* \mathrm{hr}=$ hour, $* \mathrm{pt} .=$ patient, ${ }^{*}$ Split duty= work starts at $10 \mathrm{am}$ and finished at $6 \mathrm{pm}$

\subsection{Descriptive Results}

More nursing students identified as dissatisfied (57.52\%) than satisfied (42.48\%) with the number of required total practicum hours. The major reason given for this dissatisfaction was that they felt they were asked to do non-nursing jobs and/or simple clinical nurse aid/clinical technician's job such as removing intravenous line (IV-line), bed-making, transferring patient unit to unit/radiology, checking vital signs for all patients in one unit to fill in their time. When asked for the ideal length of practicum per credit, more than one third (35.19\%) reported that having 30 hours (as opposed to 45) per week would be ideal. Students found that they have practicums in multiple cities due to lack of practicum sites and qualified organizations to complete 1000 required practicum hours for their graduation. When attending practicums in multiple cities, students experienced different levels of clinical placement quality between the cities; hospitals in big cities tended to lead to better clinical practicums. The nursing skills practiced were limited to doing chores (i.e., bed-making, checking vital sign, transporting patient to another unit) (67.1\% of respondents \%), charting (14.47 of respondents \%), providing education to patients and families $(10.53 \%$ of respondents), and giving medication $(7.89 \%$ of respondents). It is also found that half of students were not satisfied $(49.56 \%)$ with work schedule/practicum schedule: the schedule is given by hospitals. Too often, it was felt, schedules were developed based on each unit's needs as opposed to what students needed to practice or learn. Some students discussed that 
simulation-focused and/or scenario-driven classes should count as practicum hours in a one-to-one ratio (one simulation/scenario driven class equal to one practicum hour).

\section{Discussion}

Nursing students were mostly not satisfied with the quality and quantity for what they are currently having in clinical placement, specifically for the required hours at clinical sites. The most of study participants said that 1000 hours (45hours per one credit unit) of clinical practicum was too long. Rather, a few students expressed the need of simulation/scenario centered classes to be added as a regular curriculum. Also, they wanted those in-class activities to be counted as one on one (hours of clinical practicums) so that the total hours spending on sites, passing time meaninglessly, could be decreased. In fact, Kuiper and her colleagues (2010) reported that the number of required hours of clinical placement affects the quality of its experience. However, no following study has been conducted to research the most appropriate and effective amount of time for clinical placement. Thus, this study starts to fill the gap of current state of the science. Research on decision about the most desirable amount of practicum hours is warranted with the current emergency state in availability of clinical sites for practicums. For this, political supports should be also explored.

In the United States, the required number of clinical practicum hours varies between states, ranging from 450 to 1300 (https://www.ncsbn.org/Vol_24_web.pdf). In Texas, for example, the requirement is 840 hours, and it includes time spent on nursing skills, in computer/simulation laboratories, and with faculty-supervised hands-on patient care in a variety of clinical settings. Additionally, most states count clinical-based in-class activity as clinical practicum hours in one-to-one ratio. When adjusting for that, clinical practicum on-site hours needed in Texas would decrease to 500-600 to meet the licensing requirements (http://www.thecb.state.tx.us/reports/PDF/8147.PDF?CFID=52043241\&CFTOKEN=63528610).

On the other hand, the required clinical hours in S. Korea is 1000 hours prior to students' graduation all of which currently need to be at clinical sites. Lately, the number of nursing colleges has been surged in Korea. As a result, there are about 25,000 graduates every year and this is the number doubled up compare to the one in 1995 . However, the number of health organization and hospital where clinical practicums can occur has not increased. It became burdens to hospitals/health organizations since they have to take more nursing schools for the students' clinical placement. On average, one tertiary hospital takes about seven nursing colleges in average letting nursing schools have their students fulfill their clinical practicum hours (Song \& Kim, 2013). Therefore, it is barely expected for students to have quality clinical placement. Some have criticized that clinical placement becomes like a 'packing holes (required clinical hours)' and difficult to expect having quality clinical activities.

Because of the lack of suitable sites to meet the demand, it would rather be better to drastically decrease the required hours and construct a concrete proposal for the methods for how to replace the clinical hours via in-class clinical activities than letting students pass time meaninglessly. The effectiveness of simulation-centered classes has been proven over the past decade (Goldenberg et al., 2005; Ko \& Kim, 2014; Rutten et al., 2013). The need for scenario-centered classes has also been an important topic among nursing scholars in recent years (Goldenberg et al., 2005; Ko \& Kim, 2014; Rutten et al., 2013). Although simulation/scenario-centered classes conducted in an institutional lab or classroom have been approved as clinical practicum hours in the United States, not many Asian countries have done the same. Many reports stated that simulation/scenario centered class develop students' competency and confidence dramatically. These competency and confidence in implementing nursing skills are core values of nursing students to achieve prior to their graduation (Bucknall et al., 2016; Stayt et al., 2015; Khalaila, 2014). It is recommended the simulation/scenario centered class hours to be counted towards the total hours of clinical placement.

While this study fills big gaps in the current nursing knowledge, it has some limitations. There is a difficulty in generalizing findings because the sample was collected via convenience sampling. Furthermore, the non-randomized study sample was collected from eleven universities that were not randomly selected from all the nursing colleges in South Korea. Moreover, each hospital uses a different curriculum with their nursing students, thus leading to participants having different clinical experiences from which they were drawing their responses. These limits suggest that the study results should be interpreted carefully. Still, the benefits from this study outweigh the limitations. Quality clinical placement became a major topic among nursing scholars once demand of clinical placement became a global issue. In the lack of clinical sites with that much hours of required practicums make quality clinical placement difficult to be occurred. Not only the collaboration between clinical sites and nursing school but political endeavor should be also accompanied with in the future for the issue of quality clinical placement. This warrants future nursing research designed to tailor the best way (i.e., the most appropriate hours of clinical placement, count scenario/simulation-based-in class activity as clinical practicum by $1: 1$ ratio) for nursing students to experience quality clinical placement to fulfill quality clinical experience. 


\section{References}

Ahn, W., Ahn, J., \& Park, E. (2009). The functional effect of multidirectional exercise program in Parkinson's disease patients. Journal of Sport and Leisure Studies, 35, 791-99.

Arieli, D. (2013). Emotional work and diversity in clinical placements of nursing students. Journal of Nursing Scholarship, 45(2), 192-201. https://doi.org/10.1111/jnu.12020

Betony, K. (2012). Clinical practice placements in the community: A survey to determine if they reflect the shift in healthcare delivery from secondary to primary care settings. Nurse Education Today, 32(1), 21-26. https://doi.org/10.1016/j.nedt.2011.01.010

Bucknall, T., Forbes, H., Phillips, N. M., Hewitt, N. A., Cooper, S., \& Bogossian, F. (2016). An analysis of nursing students' decision-making in terms during simulations of acute patient deterioration. Journal of Advanced Nursing, 72(10), 2482-2494. https://doi.org/10.1111/jan.13009

Cheng, C., \& Liou, S. (2013). Perceptions of clinical competence among nurse pre-graduates: Do different types of nursing programs make a difference? Journal of Nursing Education and Practice, 3(9), 139-146. https://doi.org/10.5430/jnep.v3n9p139

Courtney-Pratt, H., Fitzgerald, M., Ford, K., Johnson, C., \& Wills, K. (2013). Development and reliability testing of the quality clinical placement evaluation tool. Journal of Clinical Nursing, 23, 504-514, 5-4-514.

Forber, J., Digiancomo, M., Davidson, P., Cater, B., \& Jackson, D. (2015). The context, influences and challenges for undergraduate nurse clinical education: Continuing the dialogue. Nurse Education Today, 35, 1114-8. https://doi.org/10.1016/j.nedt.2015.07.006

Ford, F., Courtney-Pratt, H., Marlow, A., Cooper, J., Williams, D., \& Mason, R. (2016). Quality clinical placements: The perspectives of undergraduate nursing students and their supervising nurses. Nurse Education Today, 37, 97-102. https://doi.org/10.1016/j.nedt.2015.11.013

Goldenberg, D., Andrusyszyn, M., \& Iwasiw, C. (2005). The effect of classroom simulation on nursing students' self-efficacy related to health teaching, Journal of Nursing Education, 44(7), 310-4.

Khalaila, R. (2014). Simulation in nursing education: An evaluation of students' outcomes at their first clinical practice combined with simulations. Nurse Education Today, 34(2), 252-258.

Ko, E., \& Kim, H. (2014). Effects of multi-mode simulation learning on nursing students' critical thinking disposition, problem solving process, and clinical competence. Korean Journal of Adult Health, 26(1), 107-116. https://doi.org/10.7475/kjan.2014.26.1.107

Kuiper, R., Murdock, N., \& Grant, N. (2010). Thinking strategies of baccalaureate nursing students prompted by self-regulated learning strategies. Journal of Nursing Education, 49(8), 429-436.

National Council of State Board of Nursing Research Brief. (2006). A national survey on elements of nursing education, 24. Retrieved December 1, 2016, from https://www.ncsbn.org/Vol_24_web.pdf

Rutten, N., Joolingen, W. R., \& Van der Veen, J. T. (2012). The learning effects of computer simulations in science education. Computers \& Education, 58(1), 136-153. https://doi.org/10.1016/j.compedu.2011.07.017

Song, J., \& Kim, M. (2013). Study on clinical education for nursing in hospitals in Korea. Journal of Korean Academy Society Nursing Education, 19(2), 251-264. https://doi.org/10.5977/jkasne.2013.19.2.251

Stayt, L., Merriman, C., Ricketts, B., \& Simpson, T. (2015). Recognizing and managing a deteriorating patient: A randomized controlled trial investigating the effectiveness of clinical simulation in improving clinical performance in undergraduate nursing students. Journal of Advanced Nursing, 71(11), 2563-2574.

Texas Board of Nursing. (2016). Legislative recommendations. Retrieved December 1, 2016, from http://www.thecb.state.tx.us/reports/PDF/8147.PDF?CFID=52043241\&CFTOKEN=63528610

\section{Copyrights}

Copyright for this article is retained by the author(s), with first publication rights granted to the journal.

This is an open-access article distributed under the terms and conditions of the Creative Commons Attribution license (http://creativecommons.org/licenses/by/4.0/). 